\title{
ABCD Analysis of Recently Announced New Research Indices
}

\author{
P. S. Aithal \\ Srinivas Institute of Management Studies, Pandeshwar, Mangalore - 575001, India \\ E-Mail: psaithal@gmail.com
}

Type of the Paper: Research Paper.

Type of Review: Peer Reviewed.

Indexed in: OpenAIRE.

DOI: http://dx.doi.org/10.5281/zenodo.583644.

Google Scholar Citation: $\underline{\text { IJMTS }}$

\section{How to Cite this Paper:}

Aithal, P. S. (2016). ABCD Analysis of Recently Announced New Research Indices. International Journal of Management, Technology, and Social Sciences (IJMTS), 1(1), 5971.

DOI: http://dx.doi.org/10.5281/zenodo.583644.

International Journal of Management, Technology, and Social Sciences (IJMTS)

A Refereed International Journal of Srinivas University, India.

(C) With Authors.

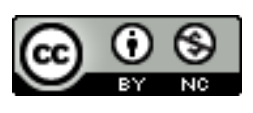

This work is licensed under a Creative Commons Attribution-Non Commercial 4.0 International License subject to proper citation to the publication source of the work.

Disclaimer: The scholarly papers as reviewed and published by the Srinivas Publications (S.P.), India are the views and opinions of their respective authors and are not the views or opinions of the SP. The SP disclaims of any harm or loss caused due to the published content to any party. 


\title{
ABCD Analysis of Recently Announced New Research Indices
}

\author{
P. S. Aithal \\ Srinivas Institute of Management Studies, Pandeshwar, Mangalore - 575001, India \\ E-Mail: psaithal@gmail.com
}

\begin{abstract}
The ability of a researcher and quality of research publications are generally measured by the number of research publications and the number of citations they receive during a given observation period. There are a number of research indices commonly used to assess the ability and hence the quantity of research along with the quality of a research publication. Research indices are calculated based on either citation values of research publications of a research scholar or the number of research papers published by a research scholar for a given period. Apart from generally used citation indices like H-index, i10-index, G-index, and based on argument on why certain research publications do not attract citations initially for some years, it is found that the best method of identifying the contribution to research is calculating the annual research index for an author by considering the annual research publications. Recently, we have suggested some of the new research indices used for calculating research productivity of individuals as well as a team of people in an organization which include ARPIndex - (Annual Research Publication Index), RC-Index - (Research Continuation Index), RE-Index (Research Expansion Index), Project Productivity Index, and Cost Index. In this paper, we have made an attempt to study these five indices by using our own technique of qualitative analysis of a system or concept called ABCD analysis/listing.
\end{abstract}

Keywords: ABCD analysis, Research indices, ARP-Index, RC-Index, RE-Index, Project Productivity Index, Cost per paper Index.

\section{INTRODUCTION :}

Innovations in higher education teaching learning processes and innovations in research are two areas of importance in higher education organizations including universities. There are many attempts is improving the quality of higher education by managing such institutions effectively [1-15]. Through managing people in organizations using Organizational performance theory A [16-22] and measuring the research productivity using Theory ABC [23-30], organizations can improve the research output. Based on competition for higher educational institutional ranking, the institutions set their priorities to research along with higher education, allocate funds for the research projects, and also encourage the faculty members to attract research project funds from both government schemes and from industries. The success of such research projects funded can be evaluated by studying the research publications and/or patents generated from those projects. The success of the organizations through research publications can be evaluated using impact factors and citation indices whereas the patents can be evaluated based on its ability of commercialization. Similarly, since several years, journals have been ranked based on their relative importance by their journal impact factor, but that system has been much commented and criticized. The importance placed on the journal impact factor, calculated by the average number of citations per article in the previous two years, has led to many journals manipulating the system. There are several citation indices that are used to assess the value/quality of a research publication or the research impact of an author or a journal. The evaluation these indices showed that there 
is a need for more sensitive and comprehensive indices that can take into considerations all the factors that may impact a research publication or author. In general, presently, the quality and effectiveness of research output and hence research publications are measured based on their citation indices.

\section{PURPOSE OF RESEARCH INDICES :}

In many cases, the research index for a research paper is calculated based on number of citations the research paper received. The research index of a research scholar is calculated based on the number of research papers published by that research scholar for a given period. There are many research indices developed by many researchers which include H-, i10-, G-, H(2)-, HG-, Q2-, AR-, Mquotient, M-, W-, Hw-, E-, A-, R-, W-, Jindex, etc. [31-32]. Out of these citation-based research indices, h-index, G-index and i10index are commonly used in some of the Citation databases. The citation based research indices calculated on of a paper or number of papers of an author has both merits and demerits. The citation index may be less for good paper or papers of an author due to following reasons [33]:

(1) The research paper topic may be unique and only few people/groups are doing research on that topic.

(2) The paper may not easily available for publics download in the journal website (not open access journal), in various databases, or due to copyright transfer from author to published journal.

(3) The research paper might have completed the entire issue of the research and no further research in that topic might be possible.

(4) Some general papers in emerging field, review papers on various futuristic field are able to attract more citations compared to a paper in a new field.

(5) If a research paper has ability to attract others and opens further new opportunities for research, is naturally motivates new research in same area or related areas.

\section{ABCD ANALYSIS OF NEWLY PROPOSED RESEARCH INDICES :}

To address the above mentioned constraints of citation indices, it is argued that the best method of identifying the contribution to research is calculating the annual research index for an author by considering the annual research publications. Accordingly, based on annual research index of an author, his average research contribution for five years, or ten years, or twenty years or any desired period can be determined. Recently, we have suggested some of the new indices to be used for calculating research productivity of individuals as well as a team of people in an organization. In this section, we have analysed the advantages, benefits, constraints, and disadvantages of these indices using our own developed ABCD analysis/listing framework [33- 44].

(1) ARP-Index - (Annual Research Publication Index):

The number of research publications of a researcher during a given period shows his/her active participation in research. In the era of publish or perish, if researcher fails to publish research papers by setting the target, they cannot compete with others in the race. Annual Research Publication index (ARP-index) is based on the annual research productivity of an author, or group of authors, or a research organization [45]. ARP index gives the weighted average of publications for a given year as the time period. This index will give annual research performance of any year (or any specific time period) of an author without considering the citations by considering the fact that usually the citations for a paper takes a long time and is variable quantity with time. This index is more useful for quick comparison of many researchers working in same or related fields for a given period of observation. This index will also stimulate the researchers to set the target for a given time period through proper planning to improve their annual research productivity. ARP-index makes use of ABC model of research productivity [23-30]. It is the weighted average of scholar's annual publications. The ARP index is exactly equal to annual research index $(\alpha)$ of a given person. ARP-index = annual research index $(\alpha)=[(2 \mathrm{~A}+5 \mathrm{~B}+$ $1 C) / 8$ ], where $\mathrm{A}$ is number of Articles published in refereed ISSN numbered journals during a given year, B is number of Books published with an ISBN number during a given year, and $\mathrm{C}$ is number of book Chapters or Case studies published with DOI during a 
given year. The ARP index can be calculated for a researcher, for a group of researchers/department or for a given organization. For a group of researchers / department or for a given organization, ARPindex can be calculated by considering a number of researchers $(\mathrm{N})$ in the group or in that organization. Then ARP-index becomes $[(2 \mathrm{~A}+5 \mathrm{~B}+1 \mathrm{C}) / 8] / \mathrm{N}$. ARP-index can be used to compare researchers annual productivity for a given time period and the annual research output of higher education and research organizations [33].

ABCD Listing Analysis of ARP-index :

(1) Advantages :

- ARP index motivates the researchers to set their annual target.

- Even though the research topics cannot be compared between different researchers/subjects, ARP index can be used to compare researchers in terms of their commitments towards publication.

- ARP index does not differentiate the papers published with different publishers so that international publishers who take the copyright of research publications as well as charges heavily as publication charges will not get any weightage.

- ARP index is independent on citation which is proportional to time after publication so that the value of ARP index is fixed for a given time and independent on progress in time.

- ARP index depends not only number of research papers published, but it counts number of books published, number of book chapter published, and number of case studies published so that all scholarly work of an author will be counted.

- This index is more useful for quick comparison of many researchers working in same or related fields for a given period of observation.

- ARP index can be calculated for a group/department or for an organization to calculate its research contribution annually or for a given period.

- ARP index is used to compare research performance of researchers irrespective of their subject, experience, age, gender, and country background.

- Since ARP index is independent on number of citations, it is not dependent on researchers working background like institutional repute, country background, collaborators, number of researchers in the area of research etc.

- ARP-index allows the institutional ranking agencies to decide the performance of the organizations for ranking.

- Calculation of ARP-index is easy and straight forward so that every researcher can calculate his/her ARP-index quickly without depending on citation value provided by various analytical websites.

\section{(2) Benefits :}

- ARP-index allows a researcher to count the research performance every year for self evaluation.

- ARP index of a researcher can be improved by himself by focusing on more research work and by means of hard work.

- Research organizations can be compared in terms of their research output based on their total value of ARP-index.

- Researchers who work in new and unique area need not worry on citation of their work and hence can maintain their monopoly.

- Since the ARP-index is straight forward and depending on number of publications with appropriate weightage which is known to the authors with more certainty compared to citation based indices, ARP-index is more reliable. Hence it is more acceptable to use in individual and institutional ranking.

- All the scholarly publications like journal publications, books published, book chapters published and case studies published are accounted in ARP index calculation.

- ARP index does not allow researchers to take rest after a bunch of publications during their young period. Professors, Deans, Directors of the institutions will register low ARP index if they fails to involve in active research and hence cannot get advantages of their old research like citation based indices. Hence performance measurement based on ARP index keeps everybody active in research irrespective of their age and position.

- Consideration of ARP indexing in organizational research comparing to other indices decreases the publication cost of the researchers.

- Encourages more research publications by every researcher in the organization which 
will results in increased organizational research output.

\section{(3) Constraints :}

- Heavy pressure on every researcher in organizations.

- No consideration of age, experience, and quality of research.

- All publications of similar category are given equal weightage which will be sometimes criticized.

- Research publications earlier than the period under consideration would not be taken for calculation of ARP index unlike citation index and hence criticized.

- Some of the publishers take long time for review and final publication of papers which affect the research and number of publications of the scholar.

\section{(4) Disadvantages:}

- Encourages unfair competition sometimes.

- May encourage long author list for each publication to take the advantage of increased number of publications.

- May create unethical competition to increase the number of publications.

- Focus on research may affect the commitment on teaching and training.

- Due to enhanced pressure on research publications, many researchers who are slow in publications may quit the profession.

(2) RC-Index - (Research Continuation Index):

Research continuation index encourages selfcitation. As per the general definition, selfcitation is a process of citing some of the old published papers of the same authors in present paper if they are relevant and appropriate to mention in the reference. This self-citation of related works will avoid repetition of concepts and even avoids selfplagiarism. Authors working in a unique area as monopoly researchers will not find muchpublished work by others in current research area/topic may find only their previous works as relevant to quote in the introduction as well as in literature review. Thus depending on the research topic in hand, an author can cite any published article whoever's it may be as cited article including self-citation. Thinking honestly, self-citation has nothing to do with ethics of publication until it cites relevant work and adds the weightage of current publication. Thus self-citation indicates research continuation in a given field by a given researcher or team of researchers. Accordingly, we have developed a new research index called Research Continuation index (RC-Index). RC index is planned to consider both the number of publications for a given time period and the number of selfcitation of previous articles in the publications so that one can have an idea of research continuation responsibility of an author or group of researchers or a research institution. Accordingly, RC-index is defined as the product of the number of research publications during a given period and the number of selfcitations in those published papers.

RC-index $=$ (Number of journal publications $\times$ Number of self-citations in those papers $)=(n$ $\times \mathrm{m})$, where $\mathrm{n}=$ number of journal publications of the researcher during a given period (maybe annually) and $\mathrm{m}=$ Number of self-citations in those papers during the same period.

Research Continuation index assumes that any new research work publication if it is a continuation of previous research work or the continuation of previous research topic will contain by logically the self-citation of previous works and publications. If selfcitation is zero, means the researcher is not continued his previous work/works. RC-index indicates the magnitude of activeness of researcher by his number of publications during a given period and ability of continuation of previous research topic/topics by a number of his self-citations. RC-index can be increased by a researcher by increasing his research contribution as well as effective self-citation during a given period [33].

ABCD Listing Analysis of RC-index :

(1) Advantages :

- RC index counts both number of publications for a given year and number of self citation to determine continuation of research.

- RC-index indicates the magnitude of activeness of researcher by his number of publications during a given period and ability of continuation of previous research topic/topics by a number of his self-citations.

- This indexing method encourages selfcitation.

- The value of RC-index runs to a big number as researcher increases either number of publications or number of self-citation. 
- RC-index can be used only for active researcher. For inactive researcher, RC index will be automatically zero.

\section{(2) Benefits :}

- The RC index involves simultaneous determination of both number of publications and the citations of his/her own publications.

- It indicates the activeness of researcher in both present and previous years.

- The researcher focuses on continuation of his previous research instead of choosing different areas at different times. This leads to the progress of research in a related area.

- The RC index is a whole number and its value can be increased either by increasing the number of research publications during a given period or by increasing the selfcitation.

- Self-Citation increases the citations of an author and hence his g-index and i10-index values also increase.

\section{(3) Constraints :}

- An active researcher who publishes many papers in a given year, may get RC-index value zero if he fails to continue his previous research. i. e., if self-citation is zero.

- No consideration of age, experience, and quality of research.

- All publications of similar category are given equal weightage which will be sometimes criticized.

- Research publications earlier than the period under consideration would not be taken for calculation of ARP index unlike citation index and hence criticized.

- Some of the publishers take long time for review and final publication of papers which affect the research and number of publications of the scholar.

\section{(4) Disadvantages :}

- Encourages unfair competition sometimes due to the reason of number of publications is a part of the index.

- May encourage long author list for each publication to take the advantage of increased number of publications.

- May create unethical competition to increase the number of publications.

- Some authors may try to increase their citations by means of self-citation of unrelated papers which attracts comments from ethical grounds.
- Focus on research may affect the commitment on teaching and training.

- Due to enhanced pressure on research publications, many researchers who are slow in publications may quit the profession.

(3) RE-Index (Research expansion Index) : In contrary to research continuation index (RC-index), a researcher can determine his research expansion index by knowing a number of journal publications and number of external citations during a given observation period.

RE-index $=$ (Number of Individual publications $\times$ Number of Citations on those papers by other researchers) during a given observation period.

RE-index indicates how the research topics studied by the researcher have expanded to other researchers so that they also started to work on those topics and published papers by citing the initial researcher's papers in their publications. RE-index gives equal importance on Number of publications by an author (n) and number of citations by others (p) on theses papers during a given observation time. REindex gives an idea of how quickly others have picked up the idea/research work of a particular researcher and continued research on that topic [33].

\section{ABCD Listing Analysis of RE-index :}

\section{(1) Advantages :}

- RE-index indicates how the research topics studied by the researcher have expanded to other researchers so that they also started to work on those topics and published papers by citing the initial researcher's papers in their publications.

- RE-index gives equal importance on Number of publications by an author (n) and number of citations by others (p) on theses papers during a given observation time.

- RE-index is independent on self-citation like h-index.

- RE-index can be improved by increasing the number of publications of the scholar for a given observation period.

(2) Benefits :

- RE-index gives an idea of how quickly others have picked up the idea/research work of a particular researcher and continued research on that topic.

- The dependence of RE-index on number of publications of the scholar for a given period 
stimulates the scholar to work hard to increase his/her research productivity.

- The popularity of the research topic and the possibility of further research work on a topic encourages further work and consequently attracts more citation by other researchers.

(3) Constraints :

- An active researcher, who publishes many papers in a given year, may get RE-index value zero if he fails to get citation by other researcher on those publications. i. e., if the total external citation is zero.

- No consideration of age, experience, and quality of research.

- All publications of similar category are given equal weightage which will be sometimes criticized.

- Research publications earlier than the period under consideration would not be taken for calculation of RE-index unlike citation index and hence criticized.

- Some of the publishers take long time for review and final publication of papers, which affect the research and number of publications of the scholar.

(4) Disadvantages :

- Encourages unfair competition sometimes due to the reason of number of publications is a part of the index.

- May encourage long author list for each publication to take the advantage of increased number of publications.

- May create unethical competition to increase the number of publications.

- Enhanced focus on research may affect the commitment on other activities like teaching and training.

- Due to enhanced pressure on research publications, many researchers who are slow in publications may quit the profession.

(4) Project Productivity Index (PP-index) : Many organizations do research by involving their researchers to work in externally funded projects as well as internally funded projects. Externally funded projects are given by Country government, various research agencies, or different industries. Internally funded projects are offered to researchers based on their department and on individual topics. The productivity of such project can be calculated by studying the number of research publication created/patents obtained from such projects. For such scenario, the funding agency can measure the productivity of a project using a quantity called project productivity index (PP-index). PP-index is defined as a ratio of Research productivity to Project funding. Research productivity can be measured by knowing the number of papers published or number of patents obtained from that project. If $\mathrm{n}$ is the number of journal papers published or/and patents accepted and $\mathrm{A}$ is the amount in Rs./\$ spent for completion of a research project, then PP-index $=(\mathrm{n} / \mathrm{A})$. By increasing the number of publications from a project or by decreasing the expenditure of a research project, one can increase the Project productivity index. Using this index, one can determine the total cost per publication in a given project and hence the success or failure of the project can be judged [33].

PP-index $=$ (Research Productivity $/$ Project Funding) $=(1 /$ Cost per publication $)$

\section{ABCD Listing Analysis of PP-index :}

(1) Advantages :

- PP-index encourages more publications at less cost.

- PP-index measures the research productivity.

- PP-index is a simple and straight forward way of measuring project success.

- PP-index can be a method of project funding decisions.

- Since research productivity depends on number of publications/patents, PP-index can be improved by increasing the number of publications of the scholar for a given observation period.

- PP-index can be increased by either increasing the number of research papers published by that project or by decreasing the cost of each paper publication.

(2) Benefits :

- Effective research cost control.

- Improvements in number of publications.

- Avoids unnecessary wastage of resources in Government funded/company funded projects.

- Effective measure of project performance and accountability.

- Measures the ability of a researcher to control research productivity.

- PP-index can be considered while allocating the government funded projects to the researchers \& research institutions. 
- Good researchers based on high PP-index value will get consideration in future project funding from various agencies.

\section{(3) Constraints :}

- Certain high investment projects with low \& slow yield may not give high PP-index.

- Fixed cost in certain research projects cannot be decreased.

- Cannot be used to compare the project performance in different area or subjects.

- Conceptual, theoretical, and simulation based research work gets higher PP-index compared to empirical and experimental research work.

- Project evaluation based on PP-index discourages low performers in terms of cost and research productivity.

- In PP-index calculation of researcher there is no consideration of age, experience, and administrative responsibility consideration and hence may be criticized by some senior researchers.

\section{(4) Disadvantages:}

- Encourages unfair competition sometimes due to the reason of number of publications and the cost of the project are parts of the index.

- High investment researches in Science \& Technology sometimes gives low productivity due to increased research cost per publication.

- PP-index will become low if researcher publishes the research papers in top reputed international journals due to heavy cost of open access publication.

- Project investigator will get heavy pressure to publications if the Project funder uses PPindex for project performance evaluation.

(5) Cost per Paper Index (CPP-Index):

CPP-index includes both, the cost of research and the cost of publication. Cost of the research include the cost of writing the project by gathering information and literature, cost of availing and setting up experimental setup or empirical methodology, cost of various resources used for research, cost of gathering data, analysing them and interpreting the result, Cost of writing research publication papers and patents, cost of publication fee/article processing charge for creative commons publications etc. Depending on the ability of the researcher and depending on the research methodology used for the research, the cost of research varies. The cost per paper index is a new way of seeing the research expenditure as an investment to get better output. Generally, the cost of research increases from conceptual research to theoretical research, to empirical research, to experimental research. A researcher should plan how to decrease the cost of research even if he is supported by government or public sector funding agencies due to the fact that such money is from the taxpayers of the country. Thus every research organization should seriously think on the output of every research project carried out by its researchers through a measuring scale using cost per paper index. Cost per paper/patent index gives a fair idea on the average cost of each paper publication which is the output of a research project under completion. Both research organization and researcher should plan how to decrease average cost per paper without compromising the quality. Generally based on prediction, cost per paper is lowest for conceptual based papers and highest for experiment based papers. Some experiments need huge investment on machines, technology, and materials. But such experiments should be planned to get a good amount of output. Thus while planning for investment on research, organizations should target to decrease the cost per paper/patent to increase the productivity. Ideally, the cost per research paper including publication should be zero for good research and in all practical cases it should be as low as possible.

\section{ABCD Listing Analysis of CPP-index :}

\section{(1) Advantages :}

- CPP-index alerts the researchers to decrease the research expenditure without compromising the quality.

- CPP-index encourages researcher to increase research output and hence more publications per project.

- Since ideal value of CPP-index is zero, every researcher should try to decrease their CPPindex as low as possible.

- CPP-index of a researcher indicates the average cost of all research publications during their entire life.

- CPP-index of a research project indicates the average cost of all research publications during the period of that project.

(2) Benefits : 
- CPP-index allows to know and compare the cost-effectiveness of a researcher for his life time research or the cost-effectiveness of a particular project funded by an agency.

- CPP-index based ranking of research scholars is possible.

- CPP-index gives an idea on how many researchers required for completion of a project.

- It also gives an idea on how to optimize the project cost and research productivity.

(3) Constraints :

- Measurement of cost per paper publication is a difficult task.

- Certain category researchers may get advantage due to the fact that their research area and methodology may need low investment but more productive in terms of publications.

- CPP-index allows you to degrease or control only direct cost involved in a project. The indirect cost like time and other resources utilization are not taken into account.

(4) Disadvantages :

- Some of the experimental research areas, the control of cost and the assured productivity are not guaranteed.

- In some of the research projects, due to security reasons, the research results cannot be published and hence productivity cannot be measured only based on number of publications/patents.

\section{CONCLUSION :}

The new research indices studied are useful for measuring the research performance of the researchers, organizations, and other stakeholders. The value of research index based on various research parameters is expected to boost the self-motivation of researchers working in any area. The popular research indices like hindex, i-10 index, g-index, R-index, m-index etc. have their own advantages, benefits, constraints, and disadvantages as listed in previous paper [33]. In this paper, we have studied the ABCD listing based analysis of recently developed research indices. The advantages, benefits, constraints, and disadvantages of calculating the annual research index (ARP-index) for an author by considering the annual research publications are identified and discussed. Accordingly, based on annual research index of an author, his average research contribution for five years, or ten years, or twenty years or any desired period can be determined. Similarly, the advantages, benefits, constraints, and disadvantages of calculating the Research Continuation Index (RC-Index) of an author is studied by considering the annual self citation are identified and discussed. The advantages, benefits, constraints, and disadvantages of calculating the Research expansion Index (RE-Index) of an author are studied by considering the annual external citation are identified and discussed. The advantages, benefits, constraints, and disadvantages of calculating the Project Productivity Index, and Cost per paper Index are also identified and discussed. It is found that these new indices are effective and simple in the research output of an organization. The detailed analysis of the factors affecting these indices using ABCD analysis framework are [46-55] is in progress.

\section{REFERENCES:}

[1] Aithal, P. S. \& Suresh Kumar, P. M. (2016). Teaching - Learning Process in Higher Education Institutions. International Journal of Multidisciplinary Research and Modern Education (IJMRME), 2(1), 662-676. DOI : http://doi.org/10.5281/zenodo.160956.

[2] Aithal, P. S. \& Shubhrajyotsna Aithal, (2015). An Innovative Education Model to realize Ideal Education System. International Journal of Scientific Research and Management (IJSRM), 3(3), $2464 \quad-\quad 2469 . \quad$ DOI: http://doi.org/10.5281/zenodo.61654.

[3] Aithal, P. S. \& Suresh Kumar, P. M. (2016). Maintaining Teacher Quality in Higher Education Institutions. International Journal of Current Research and Modern Education (IJCRME), 1(1), 701-711. DOI : http://doi.org/10.5281/zenodo.160946.

[4] Aithal, P. S. \& Suresh Kumar, P. M. (2015). Applying SWOC Analysis to an Institution of Higher Education. International Journal of Management, IT and Engineering (IJMIE), 5(7), 231-247. DOI : http:/doi.org/ 10.5281/zenodo.163425.

[5] P. S. Aithal, (2016). Creating Innovators through setting up organizational Vision, 
Mission and Core Values : a Strategic Model in Higher Education. International Journal of Management, IT and Engineering (IJMIE), 6(1), 310-324. DOI : http://doi.org/ 10.5281/ zenodo.161147.

[6] Aithal P. S. \& P.M. Suresh Kumar, (2016). Opportunities and Challenges for Private Universities in India. International Journal of Management, IT and Engineering (IJMIE), 6(1), 88-113.

[7] P. S. Aithal, P. M. Suresh Kumar, (2016). Teaching - Learning Process in Higher Education Institutions, International Journal of Multidisciplinary Research and Modern Education (IJMRME), 1(1), 662-676. DOI http://doi.org/10.5281/zenodo.160956.

[8] Aithal, P. S., (2015). MBA++ as a Unique \& Successful Model in Integrated Development of Business Executives. International Journal of Management, IT and Engineering, 5(7), 124-133.

[9] Aithal, P. S. (2015). Faculty Empowerment Strategies in Higher Education Institutions. International Journal of Management, IT and Engineering, 5(7), 108-115.

[10] Aithal, P. S. and Kumar, P. M. Suresh (2016). Innovations in Private Universities: A Case of Srinivas University. International Journal of Management, IT and Engineering, 6(1), 250-264.

[11] Aithal, P. S. and P., Harischandra, (2015). Quality Enhancement in Higher Education Institutions through Best Practices in Library: A Case of SIMS. International Journal of Management, IT and Engineering, 5(7), 489-505.

[12] Aithal, P. S. \& Priti Jeevan, (2016). Strategic Rethinking of Management Education : Green MBA Model, International Journal of Management, IT and Engineering (IJMIE), 6(1), 55-73. DOI

http://doi.org/10.5281/zenodo.154278.

[13] Aithal, P. S. \& Shubhrajyotsna Aithal, (2016). Impact of On-line Education on Higher Education System, International
Journal of Engineering Research and Modern Education (IJERMEI, 1(1), 225235.

DOI

http://doi.org/10.5281/zenodo.161113.

[14] Aithal, P. S. \& Jeevan Pinto, (2016). Innovations in Higher Education - A new model implemented in MCA degree programme of Srinivas University. International Journal of Scientific Research and Modern Education (IJSRME), 1(1), 275-289. DOI http://doi.org/10.5281/ zenodo. 161107.

[15] Sridhar Acharya, P. \& Aithal, P. S. (2016). Environmental Consciousness in Higher Educational Institutions : A case of SIMS, International Journal of Current Research and Modern Education (IJCRME), 1(1), 273-284, DOI : http://doi.org/10.5281/ zenodo.161083.

[16] Aithal, P. S. (2016). How to Increase Research Productivity in Higher Educational Institutions - SIMS Model. International Journal of Scientific Research and Modern Education (IJSRME), 1(1), 2016, 447-458. DOI : http://doi.org/10.5281/zenodo.161037

[17] Aithal, P. S. and Suresh Kumar, P. M. (2016). Organizational Behaviour in $21^{\text {st }}$ Century - Theory A for Managing People for Performance, IOSR Journal of Business and Management (IOSR-JBM), 18(7), 126-134. DOI: http://doi.org/10.9790/487X-18070 4126 134.

[18] Aithal, P. S. \& Suresh Kumar, P. M. (2016). Comparative Analysis of Theory $\mathrm{X}$, Theory Y, Theory Z, and Theory A for Managing People and Performance. International Journal of Scientific Research and Modern Education (IJSRME), 1(1), 803-812. DOI: http://doi.org/10.5281/ zenodo .154600.

[19] Aithal, P. S. \& Suresh Kumar, P. M. (2016). Theory A for Optimizing Human Productivity, IRA-International Journal of Management \& Social Sciences (ISSN 2455-2267), 4(3), 526-535. DOI : http://dx.doi.org/10.21013/jmss.v4.n3.p2.

[20] Aithal, P. S. \& Suresh Kumar, P. M. (2016). CCE Approach through ABCD 
Analysis of 'Theory A' on Organizational Performance. International Journal of Current Research and Modern Education (IJCRME), 1(1), 169-185. DOI: http://dx.doi.org/10.5281/ ZENODO.164704.

[21] Aithal, P. S. \& Suresh Kumar, P. M. (2016). Application of Theory A on ABC Model to enhance Organizational Research Productivity in Higher Education. International Journal of Advanced Trends in Engineering and Technology (IJATET), $1(1), \quad 142-150 . \quad$ DOI http://doi.org/10.5281/zenodo.240646.

[22] Aithal, P. S. \& Suresh Kumar P. M. (2017). Interconnecting Theory A and ABC Model of Organizational Performance. International Journal of Management, Technology and Social Sciences (IJMTS), 1(1), 1-13. DOI: http://dx.doi.org/10.5281/zenodo.268598.

[23] Aithal, P. S. \& Suresh Kumar, P.M., (2016). ABC Model of Research Productivity and Higher Educational Institutional Ranking. International Journal of Education and Management Engineering (IJEME), 6(6), 74-84, DOI: 10.5815/ijeme.2016.06.08.

[24] Aithal, P. S. (2016). Study of Annual Research Productivity in Indian Top Business Schools. International Journal of Scientific Research and Modern Education (IJSRME), 1(1), 402-414. DOI : http://doi.org/10.5281/ zenodo.161041.

[25] Aithal, P. S., Shailashree V. T \& Suresh Kumar P. M., (2016). Analysis of ABC Model of Annual Research Productivity using ABCD Framework. International Journal of Current Research and Modern Education (IJCRME), 1(1), 846-858. DOI : http://doi.org/10.5281/zenodo.62022.

[26] Aithal, P. S. (2016). Study of Research Productivity in World Top Business Schools, International Journal of Engineering Research and Modern Education (IJERME), 1(1), 629-644. DOI : http://doi.org/10.5281/zenodo. 160969

[27] Aithal, P. S. Shailashree, V. T \& Suresh Kumar, P. M., (2016). Analysis of ABC Model of Annual Research Productivity using ABCD Framework. International Journal of Current Research and Modern Education (IJCRME), 1(1), 846-858. DOI : http://doi.org/10.5281/zenodo.62022

[28] Aithal, P. S. (2016). Research Performance Analysis of Some Indian Top Business Schools Using ABC Model. International Journal of Computational Research and Development, 1(1), 70-83. DOI http://doi.org/10.5281/zenodo.163532.

[29] Aithal, P. S., (2016). Inspiring through Self-Contribution - An Analysis of How Active the Indian Top Business School Directors in Research \& Publications. International Journal of Engineering Research and Modern Education (IJERME), 1(2), 137 - 154. DOI: http://dx.doi.org/10.5281/ zenodo. 164690.

[30] Aithal, P. S., (2016). Excellence in Individual Research \& Publications : Examining the Active Role of Role models (Deans) of World Top Business Schools. International Journal of Engineering Research and Modern Education (IJERME), 1(2), 179-199. DOI: http://dx.doi.org/10.5281/zenodo. 192881.

[31] Maabreh M. and Alsmadi I. M., (2012). A Survey of Impact and Citation Indices: Limitations and Issues. International Journal of Advanced Science and Technology, 40, 35-54.

[32] Hirsch, J. E. (2005). An Index to Quantify an Individual's Scientific Research Output. Proceedings of the National Academy of Sciences of the United States of America, 102(46), 16569-16572.

[33] Aithal, P. S. (2017). Comparative Study of Various Research Indices used to measure quality of Research Publications. International Journal of Applied and Advanced Scientific Research (IJAASR), 2(1), 81-89. DOI http://doi.org/10.5281/zenodo.569763.

[34] Sridhar Acharya P. \& Aithal P. S., (2016). Concepts of Ideal Electric Energy System for production, distribution and utilization. International Journal of 
Management, IT and Engineering (IJMIE), 6(1), 367-379.

[35] Padmanabha Shenoy, and Aithal P. S., (2016). A Study on History of Paper and possible Paper Free World. International Journal of Management, IT and Engineering (IJMIE), 6(1), 337-355.

[36] Aithal, P. S., (2015). Comparative Study on MBA Programmes in Private \& Public Universities - A case study of MBA programme plan of Srinivas University, International Journal of Management Sciences and Business Research (IJMSBR), 4(12), 106-122.

[37] Aithal P. S., \& Shubhrajyotsna Aithal (2016). Impact of On-line Education on Higher Education System. International Journal of Engineering Research and Modern Education (IJERME), 1(1), 225235.

[38] Aithal P. S., and Suresh Kumar P. M., (2016). Analysis of Choice Based Credit System in Higher Education. International Journal of Engineering Research and Modern Education (IJERME), 1(1), 278-284.

[39] Varun Shenoy and Aithal P. S., (2016). Changing Approaches in Campus Placements - A new futuristic Model, International Journal of Scientific Research and Modern Education (IJSRME), 1(1), 766 - 776.

[40] Aithal, P. S. \& Shubhrajyotsna Aithal (2016). Ekalavya Model of Higher Education - an Innovation of IBM's Big Data University. International Journal of Current Research and Modern Education (IJCRME), 1(2), 190-205. DOI: http://dx.doi.org/10.5281/zenodo.19 8704.

[41] Aithal, P. S. \& Shubhrajyotsna Aithal, (2016). A New Model for Commercialization of Nanotechnology Products and Services. International Journal of Computational Research and Development, 1(1), 84-93. DOI : http://doi.org/10.5281/zenodo.163536.

[42] Aithal, P. S. \& Suresh Kumar, P. M. (2017). Challenges and Opportunities for Research \& Publications in Higher
Education. International Journal of Scientific Research and Modern Education (IJSRME), 2(1), 42-49. DOI: http://dx.doi.org/10.5281/zenodo.40 $\underline{0619}$.

[43] Vaikunth Pai T. \& Aithal, P. S., (2017). Cloud Computing Security Issues Challenges and Opportunities. International Journal of Management, Technology, and Social Sciences (IJMTS), 1(1), 33-42. DOI: http://dx.doi.org/10.5281/zenodo.569920.

[44] Krishna Prasad, K. and Aithal, P. S. (2017). A Study on Enhancing Mobile Banking Services using Location based Authentication. International Journal of Management, Technology, and Social Sciences (IJMTS), 1(1), 48-60. DOI: http://doi.org/10.5281/zenodo.583230

[45] Egghe, Leo (2006). Theory and practise of the g-index, Scientometrics, 69(1), 131-152. doi:10.1007/s11192-006-01447.

[46] Aithal P. S., Shailashree V. T., Suresh Kumar P. M., (2015). A New ABCD Technique to Analyze Business Models \& Concepts. International Journal of Management, IT and Engineering (IJMIE), 5(4), 409 - 423.

[47] Aithal P. S., Shailashree V. T., \& Suresh Kumar P. M., (2015). Application of ABCD Analysis Model for Black Ocean Strategy. International Journal of Applied Research (IJAR), 1(10), 331 337.

[48] Aithal P. S., Shailashree V. T., \& Suresh Kumar P. M., (2016). ABCD analysis of Stage Model in Higher Education. International Journal of Management, IT and Engineering (IJMIE), 6(1), 11-24.

[49] Aithaln P. S., Shailashree V.T., \& Suresh Kumar P. M., (2016). Analysis of NAAC Accreditation System using ABCD framework, International Journal of Management, IT and Engineering (IJMIE), 6(1), 30 - 44.

[50] Aithal, P. S., (2016). Study on ABCD Analysis Technique for Business Models, Business strategies, Operating Concepts \& Business Systems. International 
Journal in Management and Social Science, 4(1), 98-115.

[51] Aithal P. S., Shailashree V. T., \& Suresh Kumar P. M., (2016). Application of ABCD Analysis Framework on Private University System in India. International Journal of Management Sciences and Business Research (IJMSBR), 5(4), 159170.

[52] Aithal P. S., Shailashree V. T., \& Suresh Kumar P. M., (2016). The Study of New National Institutional Ranking System using ABCD Framework. International Journal of Current Research and Modern Education (IJCRME), 1(1), 389 - 402.

[53] Shubhrajyotsna Aithal \& Aithal P. S., (2016), ABCD analysis of Dye doped Polymers for Photonic Applications, IRAInternational Journal of Applied Sciences, 4(3), 358-378. DOI : http://dx.doi.org/10.21013/jas.v4.n3.p1.

[54] Varun Shenoy, \& Aithal P. S., (2016). ABCD Analysis of On-line Campus Placement Model, IRA-International Journal of Management \& Social Sciences, 5(2), 227-244. DOI: http://dx.doi.org/ 10.21013/ jmss. v5.n2.p3.

[55] Aithal, P. S., Shailashree V. T. \& Suresh Kumar P.M. (2016). Factors \& Elemental Analysis of Six Thinking Hats Technique using ABCD Framework. International Journal of Advanced Trends in Engineering and Technology (IJATET), 1(1), 85-95. DOI : http://doi.org/10.5281 zzenodo.240259. 